\title{
Genetic Predictors for the Development of Congenital Orofacial Clefts
}

\author{
Nadezhda I. Pavlova, $\mathrm{PhD}^{1^{*}}$; Khariton A. Kurtanov, $\mathrm{PhD}^{1}$; Aleksandra T. Diakonova ${ }^{1}$; \\ Lyubov S. Mironova, $\mathrm{PGS}^{2,3}$; Natalia A. Solovyeva, $\mathrm{PhD}^{1}$; Yigulana P. Borisova ${ }^{1}$; \\ Vladimir V. Dodokhov, $\mathrm{PhD}^{4}$; Innokenty D. Ushnitsky, $\mathrm{PhD}, \mathrm{ScD}^{2}$ \\ ${ }^{Y}$ Yakut Science Center of Complex Medical Problems \\ ${ }^{2}$ M. K. Ammosov North-Eastern Federal University \\ ${ }^{3}$ Republic hospital No. 1 - National center of medicine \\ ${ }^{4}$ Yakut State Agricultural Academy \\ Yakutsk, the Republic of Sakha (Yakutia), Russia
}

\begin{abstract}
Background: The aim of this study was to search for associations between polymorphisms of the IRF6, MDRI, and MTHFR genes and the risk of congenital orofacial cleft (OFCs) among the population of the Republic of Sakha (Yakutia).

Methods and Results: The sample of the studied individuals consisted of 94 children (46 girls and 48 boys) with OFCs and their parents ( 75 mothers and 18 fathers). The children with OFCs were divided into 3 groups. Group 1 included 48 children with cleft lip and palate (CLP); Group 2 included 22 children with cleft lip (CL); Group 3 included 24 children with cleft palate (CP). The comparison group included 156 healthy volunteers (118 women and 38 men) who did not have a history of relatives with OFCs. Analysis of the distribution of alleles and genotypes of studied SNPs in children with all OFCs and healthy children showed a significant $(P=0.000)$ difference only in MDR1 genetic variant rs1045642 SNP. The carriage of the TT genotype of the $M D R 1 \mathrm{rs} 1045642 \mathrm{SNP}$ was associated with increased risk of $\mathrm{OFCs}(\mathrm{OR}=2.711,95 \% \mathrm{CI}=1.459-5.037 ; P=0.000)$. Analysis of the frequency distribution of alleles and genotypes depending on the severity of clefts showed that the carriage of the TT genotype of the MDR 1 rs 1045642 SNP was associated with significant risk for development of CL (OR=3.114; 95\% CI $=1.123-8.634)$ and CLP $(\mathrm{OR}=2.804 ; 95 \% \mathrm{CI}=1.333-5.895)$. In children with $\mathrm{CP}$, we found significant risk with carriage of the TT genotype of the IRF6 rs2235371 SNP $(\mathrm{OR}=5.429,95 \% \mathrm{CI}=1.135-25.962 ; P=0.035)$.

Conclusion: A study of four SNPs in the IRF6, MDR1, and MTHFR genes revealed statistically significant increased risks for OFCs in carriers of the TT genotype of the MDR1 rs1045642 SNP; in addition, the carriage of the TT genotype of the IRF6 rs2235371 SNP significantly increased the risk of CP development. (International Journal of Biomedicine. 2020;10(1):50-53.)
\end{abstract}

Key Words: orofacial cleft $\bullet$ cleft lip and palate $\bullet I R F 6 \bullet M T H F R \cdot M D R 1$

\section{Abbreviations}

OFC, orofacial cleft; CLP, cleft lip and palate; CL, cleft lip; CP, cleft palate; IRF6, Interferon regulatory factor 6; MTHFR, Methylenetetra-hydrofolate reductase; MDR1, Multidrug resistance1; SNP, single nucleotide polymorphism

\section{Introduction}

Annually, about 30,000 children with congenital malformations of the face, neck and skull are born in the Russian Federation; $70 \%$ of them are anomalies of the

*Corresponding author: Nadezhda I. Pavlova, PhD. Yakut Science Center of Complex Medical Problems. Yakutsk, Republic of Sakha (Yakutia), Russia.E-mail: solnishko 84@inbox.ru maxillofacial system. The total frequency of morphological malformations in children under 1 year is approximately 27.2 per 1000 population. About $60 \%$ of them are detected in the first 7 days of life in obstetric institutions. One of the leading places among malformations is occupied by orofacial clefts (OFCs). Congenital clefts of the lip and/or palate (CLP, CL, $\mathrm{CP})$ are some of the most common birth defects in children; they can occur as isolated conditions or can be a symptom of hereditary syndromes. The average frequency of nonsyndromic 
OFCs is from 0.41 to 1.2 cases per 1000 newborns in the RF and does not significantly differ from the EUROCAT register data $(0.39-1.39){ }^{(1)}$

In most cases, congenital clefts of the lip and/or palate are multifactorial congenital malformations, where both genetic and exogenous factors are essential. Among the exogenous factors, the effects of physical and chemical factors, poor and unbalanced nutrition, hormonal disorders, poisons, a number of drugs and biological agents (viruses, bacteria and their toxins, protozoa) and other substances during pregnancy have been widely studied. Reliable information has been obtained on the effect of genetic polymorphisms of a number of genes on the risk of OFC development. Modern diagnostic methods allow us to study the factors of genetic predisposition involved in the morphogenesis of the lips and palate. This serves for the development of methods to prevent OFCs in families with a burdened history. In recent years, much attention has been paid to the study of gene polymorphism as a factor in the genetic predisposition to the development of this pathology. Reliable associations of gene variations (IRF6, MDRl, and $M T H F R$ ) with an increased risk for CLP, CL, and CP have been obtained in different populations. ${ }^{(1-5)}$

IRF6 is a protein encoded by the IRF6 gene in humans. This gene encodes a member of the interferon regulatory transcription factor family. Family members are divided into a highly conserved N-terminal helix-turn-helix DNA binding domain and a less conservative C-terminal protein-binding domain. The function of IRF 6 is associated with the formation of connective tissue, such as in the palate. A mutation in the IRF6 gene can lead to autosomal dominant Van der Wood syndrome or its associated popliteal pterygium syndrome. In addition, variants of the IRF6 gene have a demonstrated association with congenital clefts of the oral cavity. ${ }^{(1,2)}$

Functional SNPs in the MDR1 gene can affect the expression and activity of transport proteins located on the apical and basolateral surfaces of syncytiotrophoblast and endothelial cells of fetal placental fetal capillaries. These proteins are able to remove toxins or drugs from the environment that enter the mother's body, into the mother's bloodstream, and can lead to an altered response of the fetus on xenobiotics and a subsequent increase in the risk of complex genetic disorders or birth defects. ${ }^{(3)}$

The MTHFR gene, encoding the synthesis of the MTHFR enzyme, is located on chromosome 1p36.3. MTHFR plays a key role in folic acid metabolism. The rs1801133 SNP (also known as $677 \mathrm{C}>\mathrm{T}$ ) is localized in exon 4 of the MTHFR gene and is formed by the transition from cytosine (C) to thymine (T). The 222nd genetic code of the MTHFR gene changes from GCC to GTC, which leads to the replacement of alanine (Ala) with valine (Val) in the MTHFR polypeptide. Animal studies have shown that reducing the formation of methionine from homocysteine plays a key role in the development of neural tube defects. A number of studies investigated the relationship between the polymorphisms of the MTHFR gene and OFCs, but with mixed results. ${ }^{(4,5)}$

The aim of this study was to search for associations between polymorphisms of the IRF6, MDR1, and MTHFR genes and the risk of congenital OFCs among the population of the Republic of Sakha (Yakutia).

\section{Materials and Methods}

The experimental part of the work on the genotyping of the IRF6 SNPs (rs2235371, rs861019), the MDR1 rs1045642 SNP, and the MTHFR rs 1801133 SNP was performed in the Department of Molecular Genetics at YSC CMP. For the study, we used DNA samples from the collection of biomaterials of the YSC CMP (Project "The Genome of Yakutia"; No. USE_507512). The study was approved by the Ethics Committee of the Yakut Science Center of Complex Medical Problems (YSC CMP). Written informed consent was obtained from each research participant (or the participant's parent/guardian).

The sample of the studied individuals consisted of 94 children (46 girls and 48 boys) with OFCs and their parents (75 mothers and 18 fathers). The children with OFCs were divided into 3 groups. Group 1 included 48 children with CLP; Group 2 included 22 children with CL; Group 3 included 24 children with CP. About one third of the OFC children (32 patients) had a family history of the malformation. According to indications, a cytogenetic examination was performed to exclude chromosomal pathology in this group of children. The comparison group included 156 healthy volunteers who did not have a history of relatives with OFCs.

Genomic DNA was isolated from the peripheral blood leukocytes using a commercial DNA-isolation kit (Excell Biotech Corporation; Yakutsk, Russia). The study of the IRF6 SNPs (rs2235371, rs861019), the MDR1 rs1045642 SNP, and the MTHFR rs 1801133 SNP was performed by PCR and RFLP analysis.

Primer sequences, conditions for amplification, restriction pattern, and restriction enzymes for study SNPs are presented in Table 1. Genotypes were determined by analyzing the sizes of the resulting fragments by gel electrophoresis on $4 \%$ agarose gel with ethidium bromide in standard Tris-acetate buffer at $120 \mathrm{~V}$ for 1 hour. Restriction products were visualized using a gel documentation system in a Vilber Lourmat Compact UV Transilluminator (France). Electrophoretograms of the studied SNPs are presented in Figures 1,2,3 and 4.

Statistical analysis was performed using Microsoft Excel 2010. Differences in the allele distribution between the two groups were assessed by $\chi 2$ - test with Yates correction. Odds ratios (ORs) and $95 \%$ confidence intervals (CIs) were calculated. A probability value of $P<0.05$ was considered statistically significant.

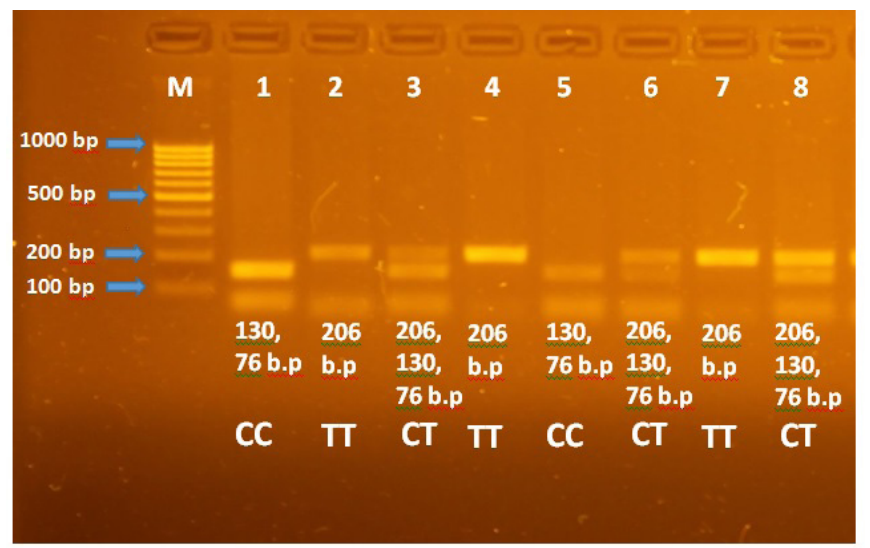

Fig. 1. A 4\% agarose gel electrophoresis of PCR-RFLP products for the MDR1 rs1045642 SNP

$M$ - marker Step 100 


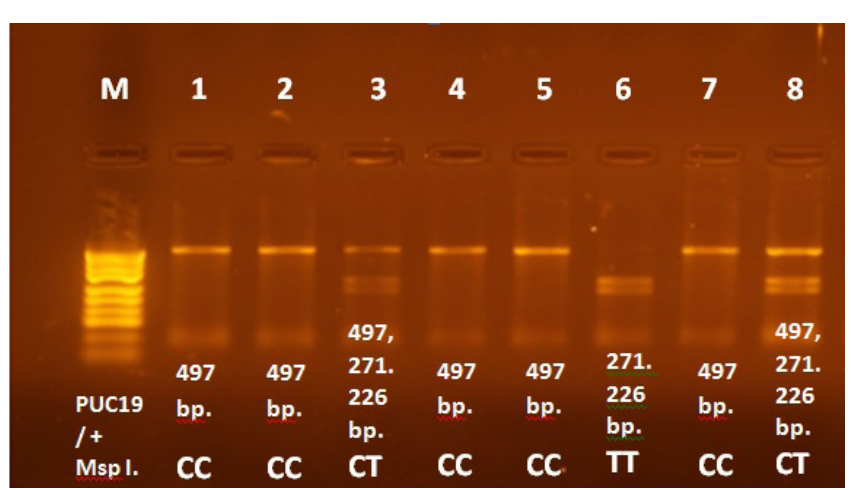

Fig. 2. A 4\% agarose gel electrophoresis of PCR-RFLP products for the MTHFR rs1801133 SNP $M$ - marker $p U C 19$ / Msp I

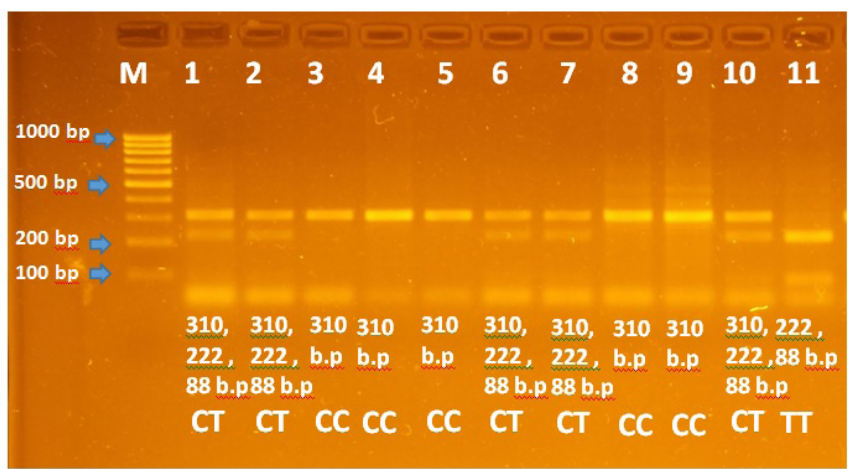

Fig. 3. A 4\% agarose gel electrophoresis of PCR-RFLP products for the IRF6 rs2235371 SNP

$M$ - marker Step 100

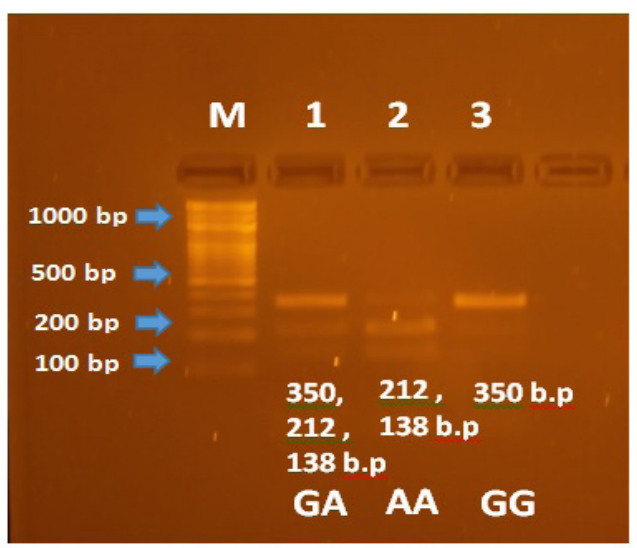

Fig. 4. A 4\% agarose gel electrophoresis of PCRRFLP products for the IRF6 rs861019 SNP

$M$ - marker Step 100

\section{Results and Discussion}

Analysis of the distribution of alleles and genotypes of studied SNPs in children with all OFCs and healthy children showed a significant $(P=0.000)$ difference only in $M D R 1$ genetic variant rs1045642 SNP. The carriage of the TT genotype of the MDR1 rs1045642 SNP was associated with increased risk of OFCs $(\mathrm{OR}=2.711,95 \% \mathrm{CI}=1.459$ 5.037; $P=0.000$ ) (Table 2).
Table 1.

Conditions for PCR-RFLP analysis

\begin{tabular}{|c|c|c|c|c|c|}
\hline SNP & Primer & $\begin{array}{l}\mathrm{AT}, \\
{ }^{\circ} \mathrm{C}\end{array}$ & $\begin{array}{l}\mathrm{AL}, \\
\mathrm{bp}\end{array}$ & $\mathrm{RE}$ & $\begin{array}{c}\text { Restriction } \\
\text { fragment length, } \\
\text { bp }\end{array}$ \\
\hline \multirow{2}{*}{ 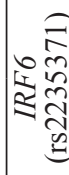 } & $\begin{array}{l}\text { F:5' - ATC AGT CCT CTG } \\
\text { TCC ATG ACG -3' }\end{array}$ & \multirow{2}{*}{61} & \multirow{2}{*}{310} & \multirow{2}{*}{ MboI } & \multirow{2}{*}{$\begin{array}{l}\text { CC: } 310 \\
\text { CT: } 310,222,88 \\
\text { TT: } 222,88\end{array}$} \\
\hline & $\begin{array}{l}\text { R:5'- GCA TGA GTC ACA } \\
\text { GGG ATG AAC -3' }\end{array}$ & & & & \\
\hline \multirow{2}{*}{ 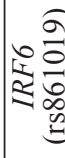 } & $\begin{array}{l}\text { F:5'-ATG ACA CCA CCA } \\
\text { TGA TGAGGGA-3' }\end{array}$ & \multirow{2}{*}{61} & \multirow{2}{*}{350} & \multirow{2}{*}{ TfiI } & \multirow{2}{*}{$\begin{array}{l}\text { GG: } 350 \\
\text { GA: } 350,212,138 \\
\text { AA: } 212,138\end{array}$} \\
\hline & $\begin{array}{l}\text { R:5'-CTA GCC ATG CAA } \\
\text { AGCTTGTCTC-3' }\end{array}$ & & & & \\
\hline \multirow{2}{*}{ 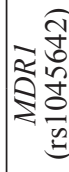 } & $\begin{array}{l}\text { F:5'-TTG ATG GCA AAG } \\
\text { AAA TAA AGC-3' }\end{array}$ & \multirow{2}{*}{54} & \multirow{2}{*}{207} & \multirow{2}{*}{ DpnI } & \multirow{2}{*}{$\begin{array}{l}\text { CC: } 130,76 \\
\text { CT: } 206,130,76 \\
\text { TT: } 206\end{array}$} \\
\hline & $\begin{array}{l}\text { R:5'-CTT ACA TTA GGC } \\
\text { AGT GAC TCG-3' }\end{array}$ & & & & \\
\hline \multirow{2}{*}{ 迹 } & $\begin{array}{l}\text { F:5'- TGG GGT CAG AAG } \\
\text { CAT ATC AGT CA -3, }\end{array}$ & \multirow{2}{*}{62} & \multirow{2}{*}{497} & \multirow{2}{*}{ TaqI } & \multirow{2}{*}{$\begin{array}{l}\text { CC: } 497 \\
\text { TC: } 497,271,226 \\
\text { TT: } 271,226\end{array}$} \\
\hline & $\begin{array}{l}\text { R:5' - CTG GGA AGA ACT } \\
\text { CAG CGA AC-3' }\end{array}$ & & & & \\
\hline
\end{tabular}

Note: $b p$ - base pairs; AT- Annealing temperature; AL - Amplicon length; RE- Restriction enzyme

Table 2.

Distribution of alleles and genotypes of studied SNPs in children with all $\mathrm{OFCs}$ and healthy children

\begin{tabular}{|c|c|c|c|c|c|}
\hline \multirow{2}{*}{$\begin{array}{l}\text { Genotype/ } \\
\text { allele }\end{array}$} & \multicolumn{2}{|c|}{ Genotype/allele frequency, $\%$} & \multirow{2}{*}{$\chi^{2}$} & \multirow{2}{*}{$P$} & \multirow{2}{*}{ OR $(95 \% \mathrm{CI})$} \\
\hline & OFCs & Control & & & \\
\hline \multicolumn{6}{|c|}{ IRF6 (rs2235371) } \\
\hline $\mathrm{CC}$ & 52.1 & 47.4 & \multirow{3}{*}{2.188} & \multirow{3}{*}{0.335} & \\
\hline $\mathrm{CT}$ & 42.6 & 50.0 & & & \\
\hline TT & 5.3 & 2.6 & & & \\
\hline $\mathrm{C}$ & 73.4 & 72.4 & \multirow{2}{*}{0.056} & \multirow{2}{*}{0.813} & \\
\hline $\mathrm{T}$ & 26.6 & 27.6 & & & \\
\hline \multicolumn{6}{|c|}{ IRF6 (rs861019) } \\
\hline AA & 18.1 & 30.8 & \multirow{3}{*}{5.29} & \multirow{3}{*}{0.071} & \\
\hline GA & 44.7 & 34.6 & & & \\
\hline GG & 37.2 & 34.6 & & & \\
\hline A & 40.4 & 48.1 & \multirow{2}{*}{2.773} & \multirow{2}{*}{0.096} & \\
\hline G & 59.6 & 51.9 & & & \\
\hline \multicolumn{6}{|c|}{ MDR1 (rs1045642) } \\
\hline $\mathrm{CC}$ & 18.1 & 10.9 & \multirow{3}{*}{15.724} & \multirow{3}{*}{0.000} & \multirow{3}{*}{$\begin{array}{c}2.711 \\
(1.459-5.037)\end{array}$} \\
\hline $\mathrm{CT}$ & 50 & 74.4 & & & \\
\hline TT & 31.9 & 14.7 & & & \\
\hline $\mathrm{C}$ & 43.1 & 48.1 & \multirow{2}{*}{1.176} & \multirow{2}{*}{0.278} & 1.223 \\
\hline $\mathrm{T}$ & 56.9 & 51.9 & & & $(0.850-1.761)$ \\
\hline \multicolumn{6}{|c|}{$M T H F R(\operatorname{rs} 1801133)$} \\
\hline $\mathrm{CC}$ & 75.5 & 70.5 & \multirow{3}{*}{0.474} & \multirow{3}{*}{0.789} & \\
\hline $\mathrm{CT}$ & 24.5 & 28.8 & & & \\
\hline $\mathrm{TT}$ & 0.0 & 0.64 & & & \\
\hline $\mathrm{C}$ & 87.8 & 84.9 & \multirow{2}{*}{0.78} & \multirow{2}{*}{0.377} & \\
\hline $\mathrm{T}$ & 12.2 & 15.1 & & & \\
\hline
\end{tabular}


Analysis of the frequency distribution of alleles and genotypes depending on the severity of clefts showed that the carriage of the TT genotype of the MDR1 rs1045642 SNP was associated with significant risk for development of CL $(\mathrm{OR}=3.114 ; 95 \% \mathrm{CI}=1.123-8.634)$ and $\mathrm{CLP}(\mathrm{OR}=2.804 ; 95 \%$ $\mathrm{CI}=1.333-5.895)$. In children with $\mathrm{CP}$, we found significant risk with carriage of the TT genotype of the IRF6 rs2235371 $\mathrm{SNP}(\mathrm{OR}=5.429 ; 95 \% \mathrm{CI}=1.135-25.962 ; P=0.035)$.

In conclusion, a study of four SNPs in the IRF6, MDRI, and MTHFR genes revealed statistically significant increased risks for OFCs in carriers of the TT genotype of the MDR1 rs1045642 SNP; in addition, the carriage of the TT genotype of the IRF6 rs2235371 SNP significantly increased the risk of CP development.

\section{Acknowledgments}

The study was carried out within the framework of the project "The study of the genetic structure and burden of hereditary pathology of populations of the Republic of Sakha (Yakutia), using the Unique scientific equipment (USE) "The Genome of Yakutia” (Reg. No. USU_507512).

\section{Competing Interests}

The authors declare that they have no competing interests.

\section{References}

1. Rafighdoost H, Hashemi M, Danesh H, Bizhani F, Bahari G, Taheri M. Association of single nucleotide polymorphisms in AXIN2, BMP4, and IRF6 with Non-Syndromic Cleft Lip with or without Cleft Palate in a sample of the southeast Iranian population. J Appl Oral Sci. 2017 Nov-Dec;25(6):650-656. doi: 10.1590/1678-7757-2017-0191

2. Bezerra JF, Silva HPVD, Bortolin RH, Luchessi AD, Ururahy MAG, Loureiro MB, et al. IRF6 polymorphisms in Brazilian patients with non-syndromic cleft lip with or without palate. Braz J Otorhinolaryngol. 2019 Jun 8. pii: S1808-8694(18)30495-6. doi: 10.1016/j.bjorl.2019.04.011

3. Omoumi A, Wang Z, Yeow V, Wu-Chou YH, Chen PK, Ruczinski I, et al. Fetal polymorphisms at the ABCB1transporter gene locus are associated with susceptibility to non-syndromic oral cleft malformations. Eur J Hum Genet. 2013 Dec;21(12):1436-41. doi: 10.1038/ejhg.2013.25.

4. Wang Y, Zheng G, Kang M, Tang W, Cai W, Huang Z. Methylenetetrahydrofolate reductase rs1801133 C>T polymorphism is association with nonsyndromic cleft lip with or without cleft palate susceptibility: A meta-analysis. Int $\mathrm{J}$ Clin Exp Med. 2017.10 (2):1734-1749.

5. Meshherjakova TI., Markova SI, Zhilina SS, Gonchakov GV, Gonchakova SG, Abramov AA, Mutovin GR. [Study of the effect of the C677T polymorphism of the MTHFR gene on the risk of nonsyndromic orofacial cleft formation]. Russian Bulletin of Perinatology and Pediatrics. 2013;3(58);38-41. [Article in Russian]. 